\title{
Abusive Head Trauma: Epidemiological Aspects and Diagnosis
}

\section{Trauma Craniano por abuso: aspectos epidemiológicos e diagnostico}

José Roberto Tude Melo ${ }^{1,2}$ Federico Di Rocco ${ }^{1}$ Estelle Vergnaud ${ }^{3} \quad$ Juliette Montmayeur ${ }^{3}$ Marie Bourgeois ${ }^{1}$ Christian Sainte-Rose ${ }^{1}$ Michel Zerah ${ }^{1} \quad$ Philippe Meyer $^{3}$

${ }^{1}$ Department of Pediatric Neurosurgery, Hôpital Universitaire NeckerEnfants Malades, Université Descartes Paris 5, Paris, France

Address for correspondence José Roberto Tude Melo, MD, Hospital

2 Pediatric Neurosurgical Unit, Hospital São Rafael, Salvador, Bahia, São Rafael, Avenida São Rafael 2152, São Marcus, Salvador, Bahia,

Brazil

3 Pediatric Surgical Critical Care Unit and Anesthesiology, Hôpital

Universitaire Necker-Enfants Malades, Université Descartes Paris 5 ,

Paris, France

Brazil CEP: 41.253-190 (e-mail: robertotude@gmail.com).

Arq Bras Neurocir 2015;34:267-273.

\section{Abstract \\ Keywords \\ - brain injuries \\ - child abuse \\ - shaken baby syndrome \\ - subdural hematoma}

\section{Resumo}

Palavras-chave

- traumatismos encefálicos

- maus-tratos infantis

- síndrome do bebê sacudido

- hematoma subdural
Objective Abusive head trauma (AHT) is defined as a severe, non-accidental traumatic brain injury. Early recognition and treatment are instrumental in limiting the immediate complications and long-term disabilities. The goal of this study was to describe our experience with traumatic head injuries in children younger than 2 years of age.

Methods We reviewed the medical records of 195 children aged under 2 years with suspected AHT who presented with a head injury without witnessed accidental trauma, between January 2008 and June 2013.

Results AHT was considered in 145 children. Familial problems $(\rho=0.008)$, cutaneous hematoma/bruising $(\rho<0.001)$, retinal hemorrhages $(\rho<0.001)$, and bone fractures $(\rho=0.04)$, were significantly more frequent in the AHT group.

Conclusions The association between the subdural hematoma and retinal hemorrhage, resulting from an unwitnessed and incoherent history of trauma, is a strong argument for AHT, particularly when associated lesions and socioeconomic risk factors are evident.

Objetivo O traumatismo craniano por abuso (AHT) é definido como uma grave lesão cerebral traumática não acidental. O reconhecimento e tratamento precoce são fundamentais para limitar as complicações imediatas e sequelas tardias. $\mathrm{O}$ objetivo deste estudo foi descrever a nossa experiência em crianças menores de 2 anos de idade, vítimas de trauma craniano.

Métodos Foram revisados os prontuários de 195 crianças com idade inferior a 2 anos com suspeita de AHT, sem trauma acidental testemunhado e com diagnostico de hematoma subdural, entre janeiro de 2008 e junho de 2013. received

May 9, 2013

accepted

August 7, 2015

published online

October 19, 2015
DOI http://dx.doi.org/

10.1055/s-0035-1565914. ISSN 0103-5355.
Copyright $@ 2015$ by Thieme Publicações License terms

Ltda, Rio de Janeiro, Brazil 
Resultados AHT foi considerado em 145 crianças. Problemas socioeconômicos familiares $(\rho=0,008)$, hematomas e lesões cutâneas $(\rho<0,001)$, hemorragias retinianas $(\rho<0,001)$, e fraturas em ossos longos $(\rho=0,04)$, foram significativamente mais frequentes no grupo de crianças com suspeita de AHT.

Conclusões A associação entre hematomas subdurais e hemorragia retiniana, resultante de uma história incoerente de trauma sem testemunhas, é um forte argumento para a AHT, particularmente quando lesões cutâneas e fatores de risco socioeconômicos forem identificados.

\section{Introduction}

Abusive head trauma (AHT), defined as a severe, non-accidental traumatic brain injury, was first described by the French forensic expert August Ambroise Tardieu in 1860, ${ }^{1}$ and occurs particularly in the first year of life. ${ }^{2-8}$ Several authors have highlighted the possibility of underestimating the diagnosis, speculating that not every child is taken to receive medical assistance and not all cases are recognized and confirmed to be AHT by the health professionals treating these children. $2,4,5,7-12$

In this study, we discuss the epidemiological profile of AHT based on our experience in traumatic head injuries on children aged under 2 years at a pediatric trauma center in Paris, France. We compare the main characteristics of AHT and non-AHT (nAHT), providing evidence to help clinicians consider and confirm this diagnosis.

\section{Materials and Methods}

\section{Study Design and Sample}

We conducted a review of the medical records of 195 consecutive children aged under 2 years with suspected AHT, treated between January 2008 and June 2013 in the Île-de-France region. The inclusion criterion was the presence of a head injury, predominantly a subdural hematoma (SDH) identified by a computed tomography (CT) scan, without a clear history of witnessed accidental trauma or evidence of a metabolic or infectious disease or coagulopathy.

All children enrolled in this study were admitted to a Level I pediatric trauma center (Hôpital Universitaire NeckerEnfants Malades, Paris, France). The same protocol was applied for all children. After in-hospital stabilization, seizure control or systematic prophylactic treatment, endotracheal intubation, mechanical ventilation, and invasive monitoring probe insertion (central venous and arterial line catheters) were undertaken as necessary, and all children underwent CT scanning. Complete biologic screening eliminated associated metabolic and infectious diseases or coagulopathies. Transcranial Doppler (TCD) examination, electroencephalography (EEG), ophthalmologic examination, and whole-body bone radiography were performed as soon as possible. Parents were systematically evaluated by a specialized team of social workers and psychologists. Data about parents or caregivers were recorded for age and familial, marital, educational, and socioeconomic status.

After the completion of exploration and social evaluation, all cases of suspected AHT were discussed by a multidisciplinary panel consisting of neurosurgeons, intensive care specialists, pediatricians, forensic specialists, psychologists, nurses, and social workers. This multidisciplinary panel has been described in other French studies. ${ }^{12}$ After careful data analysis by the panel, children were classified into two groups:

- Group 1 (nAHT Group): where a potential mechanism of trauma (mainly falls and other direct impacts on the head) could be identified through caregivers, parents, or witnessed reports and could be compatible with the observed lesions.

- Group 2 (AHT Group): where the reported cause of trauma was inconsistent with the severity of the clinical presentation, and the history was not clarified during hospitalization. All these cases were reported as required by law to the state prosecutor and further investigated by a specialized police squad.

For the purpose of this analysis, the following characteristics of victims and potential perpetrators of AHT were particularly recorded:

- In parents or caregivers:

- Young age, history of family violence, alcoholism, drug abuse, unemployment, financial problems, or other factors that may compromise the balance of the family. ${ }^{9,12,13}$

- Parents seeking medical assistance with prior emergency department visits. ${ }^{14}$

- The child's representation in the family.

- Parental reactions after the announcement of diagnosis.

- In children:

- Age, sex, prematurity, prior hospitalization, and comorbidities such as neurologic disabilities or other diseases described as risk factors. ${ }^{12,15}$

- Recent medical history and initial clinical presentation.

- The presence of initial seizures and/or status epilepticus. $^{16}$

- Clinical evolution, ophthalmologic exams, skeletal radiographs, and EEG findings. ${ }^{16}$ 
- CT scan results: the estimated thickness of SDH, its localization, scan density, and/or associated lesions. $^{11,16,17}$

After a complete radiologic examination, AHT was classified into three predefined categories ${ }^{6}$ :

- Battered child syndrome: head injury associated with an extracranial lesion.

- Shaken baby syndrome: SDH and/or subarachnoid hemorrhage with no focal lesion or skull fracture.

- Shaking-impact baby syndrome: fractures of the skull or subgaleal hematomas in a shaken baby.

Follow up was ensured in all children for at least 6 months, and cognitive and/or motor neurologic deficits, epilepsy, developmental and behavioral disorders, and visual disturbances were evaluated by a multidisciplinary team. ${ }^{16,18}$

\section{Statistical Analysis and Ethical Aspects}

Some results were presented in a descriptive manner, without statistical analyses. When necessary, proportions were compared with $\rho<0.05$ considered statistically significant. Fisher's exact test or the chi-squared $\left(\chi^{2}\right)$ test were applied when appropriate, with one degree of freedom. For elaboration and analysis of the database, we used EpiInfo Version 7, publicdomain statistical software for epidemiology developed by the Centers for Disease Control and Prevention (Atlanta, GA, USA). This research adhered to legal guidelines regarding research on human beings and respected and ensured the confidentiality of participants. This single-center study was conducted in agreement with French law (institutional review board approval was granted, no informed consent was deemed necessary, and databank information was anonymized).

\section{Results}

We examined the medical records of 195 consecutive children aged under 2 years, with head injuries initially consid- ered AHT, reviewed by our institutional multidisciplinary panel between January 2008 and June 2013. In 50 cases (26\%), after further investigation of the reported details of the accident, coherence was found between the accounts of parents or caregivers and medical findings. None of these children presented evidence of inflicted extracranial trauma (unexplained bruising, hematoma, or burns), and all were considered nAHT. The remaining 145 children (74\%) were considered potential victims of AHT.

An examination of family characteristics revealed that the median parent age did not differ significantly between the nAHT (Group 1) and AHT (Group 2) groups (Group 1 Fathers: median age, 35 years; range, 26-60 years versus Group 2 Fathers: median age, 32 years; range, $17-53$ years and Group 1 Mothers: median age, 31 years; range, 21-41 years versus Group 2 Mothers: median age, 30 years; range, $17-49$ years). A history of conjugal or familial violence, unemployment, alcoholism, or drug abuse was evident in $20 \%$ of the parents in the group 1 versus $42 \%$ of those in group $2(\rho=0.008$; $x^{2}=6.89$; - Table 1). - Table 2 details the main complaints that led parents or caregivers to seek medical assistance and the presentation upon hospital admission.

An examination of children's characteristics revealed a median age and male predominance common to both groups (Group 1: median age: 5.7 months; range, 5 days to 19 months versus Group 2: median age, 5.9 months; range, 1-23 months and male, $76 \%$, female $68 \%$ ). In the group $1,36 \%$ of the children had been recently evaluated by a physician prior to admission compared with $44 \%$ in the group 2 ( $\left.\rho=0.4 ; \chi^{2}=0.70\right)$. Other intercurrent diseases or comorbidities were recorded in $46 \%$ of the group 1 and $37 \%$ of the group 2 . The main comorbidity described was previously noted as macrocephaly (25\% in each group), defined as two points over the standard for age and qualified as external hydrocephaly (benign childhood hydrocephalus) before the occurrence of head trauma. Prematurity was noted in $4 \%$ of the nAHT children and $7 \%$ of the AHT children $(\rho=0.7)$ and did not significantly differ from the nationally reported rate.

Table 1 Epidemiological profile of 195 families researched because of suspected abuse, between January 2008 and June 2013 (Paris, France)

\begin{tabular}{|l|l|l|}
\hline Epidemiological characteristics & nAHT $(\boldsymbol{n}=\mathbf{5 0})$ & AHT $(\boldsymbol{n}=\mathbf{1 4 5})$ \\
\hline Father's age (years) & & \\
\hline Median age (variation) & 35 (ranging from 26 to 60 years) & 32 (ranging from 17 to 53 years) \\
\hline Mother's age (years) & & \\
\hline Median age (variation) & 31 (ranging from 21 to 41 years) & 30 (ranging from 17 to 49 years) \\
\hline Origin & & \\
\hline Ile de France $\mathrm{n}(\%) \dagger$ & $48(96)$ & $125(86)$ \\
\hline Other regions $\mathrm{n}(\%)$ & $2(4)$ & $20(14)$ \\
\hline Social economical or familiar problems $\dagger \dagger \mathrm{n}(\%)^{*}$ & $10(20)$ & $61(42)$ \\
\hline
\end{tabular}

Abbreviations: AHT, abusive head trauma; nAHT, nonabusive head trauma.

†Region of Ile de France (including Paris, Essonne, Hauts-de-Seine, Seine-Saint-Denis, Seine-et-Marne, Val-de-Marne, Val-d'Oise, Yvelines).

†TConsidering according to social worker evaluation: family violence, alcoholism or others drug use, unemployment, and other factors that may compromise the balance of the family.

* $\rho=0.008 ; x^{2}=6.89 ; 1$ degree of freedom. 
Table 2 Main complaints referred that led parents or caregivers to seek medical care, and the findings on hospital admission for 195 children admitted with suspicion of abusive head trauma, between January 2008 and June 2013 (Paris, France)

\begin{tabular}{|l|l|l|}
\hline Main symptoms and clinical features & $\begin{array}{l}\text { Regarding parents or caregivers } \\
\mathbf{n}(\%)\end{array}$ & $\begin{array}{l}\text { Findings on hospital admission } \\
\mathbf{n}(\%)\end{array}$ \\
\hline Unspecific complains $^{\text {a }}$ & $40(20)$ & $8(4)$ \\
\hline Neurological abnormalities $^{\text {b }}$ & $64(33)$ & $151(78)$ \\
\hline Other or not related & $91(47)$ & $36(18)$ \\
\hline Total & $195(100)$ & $195(100)$ \\
\hline
\end{tabular}

arritability, vomiting, poor feeding, malaise.

${ }^{b}$ Considering if children had bulging fontanels, sunset eyes, or Cushing triad (bradycardia, arterial hypertension and respiratory disorders), was unresponsiveness or hypotonic or a history of epileptic seizures.

CT examination identified SDH in $90 \%$ of the children in Group 1 and $97 \%$ of the children in Group 2. Of the children in the AHT group ( $n=145$ ), only one child could be classified as a potential victim of battered child syndrome, whereas 132 (91\%) were determined to have shaken baby syndrome, and 12 (8\%) were determined to have shaking-impact baby syndrome. According to clinical evaluations, no children in Group 1 and $33(23 \%)$ children in Group $2(\rho<0.001)$ exhibited signs of potential abuse or impact (such as cutaneous bruises in various stages of absorption or burns). Children in Group 2 exhibited retinal hemorrhage (RH) more frequently (79\% versus $10 \% ; \rho<0.001 ; \chi^{2}=72.5$ ), with bilateral and diffuse hemorrhage in $77 \%$ of cases, whereas RH was only focal in Group 1. Associated extracranial skeletal fractures were noted in $18 \%$ of participants in Group 2 and 6\% of Group $1(\rho=0.04)$. The main characteristics of children with AHT and nAHT are presented in - Table 3.

Children with AHT tended to have a more severe initial presentation and worse outcome than their nAHT counterparts. Long-lasting or recurrent seizures consistent with status epilepticus were more frequently observed in cases of AHT compared with cases of nAHT (66\% versus $20 \%$; $\rho<0.001$ ). Motor, behavioral, cognitive, or visual disabilities persisting for at least 6 months after trauma were identified in $10 \%$ of the nAHT children and in $36 \%$ of the AHT children $\left(\rho=0.001 ; \chi^{2}=10.6\right)$. Death occurred in six children in Group 2 (4\%) and none in Group 1.

\section{Discussion}

Abuse against children may include physical aggression, negligence, and emotional or sexual abuse. ${ }^{11,19}$ Different qualifications are used for AHT, making the evaluation of its real incidence more difficult. Non-accidental head injury or inflicted traumatic brain injury are commonly used to define AHT. ${ }^{3,6,7}$ The incidence varies according to the region studied and is influenced by socioeconomic and cultural factors. $^{2,4,5,7-9,11,20,21}$ In the United States, it is estimated to occur in $\sim 17: 100,000$ people/year, and in the United Kingdom this figure is $21: 100,000$ people/year. ${ }^{4}$ In our hospitalbased series from 2008, 26 new cases were observed each

Table 3 Profile of 195 children examined by a multidisciplinary group, with initial suspicious of abuse, between January 2008 and June 2013 (Paris, France)

\begin{tabular}{|l|l|l|l|}
\hline Characteristic & $\begin{array}{l}\text { nAHT } \\
(\mathbf{n}=\mathbf{5 0}) \\
\mathrm{n}(\%)\end{array}$ & $\begin{array}{l}\text { AHT } \\
(\mathbf{n}=\mathbf{1 4 5}) \\
\mathrm{n}(\%)\end{array}$ & $\boldsymbol{\rho}$ \\
\hline External signs of abuse $^{\mathrm{a}}$ & 0 & $33(23)$ & $<0.001$ \\
\hline Presence of retinal hemorrhage $^{\text {Unilateral }}$ & $5(10)$ & $115(79)$ & $<0.001$ \\
\hline Bilateral & $5(100)$ & $27(23)$ & \\
\hline Bone fractures other then skull $^{\mathrm{b}}$ & 0 & $88(77)$ & \\
\hline Abnormalities at Electroencephalogram $^{c}$ & $3(6)$ & $26(18)$ & 0.04 \\
\hline Long term neurological and/or ophthalmological disabilities $^{\mathrm{d}}$ & $10(20)$ & $96(66)$ & $<0.001$ \\
\hline
\end{tabular}

Abbreviations: AHT, abusive head trauma; nAHT, nonabusive head trauma.

${ }^{a}$ Cutaneous bruises in various stages of absorption, abrasions and burns.

${ }^{b}$ Fractures in other regions of the body such as ribs and limbs detected in skeletal radiographs.

${ }^{c}$ We considered any kind of abnormalities described at the first Electroencephalogram.

${ }^{\mathrm{d} C o n s i d e r i n g ~ m o t o r, ~ b e h a v i o r a l, ~ c o g n i t i v e ~ o r ~ v i s u a l ~ d i s a b i l i t i e s ~ t h a t ~ p e r s i s t ~ f o r ~ a t ~ l e a s t ~ t h r e e ~ m o n t h s ~ a f t e r ~ t r a u m a . ~}$

${ }^{\dagger}$ Considered 139 survivals (50/139). 
year. This represents a slightly reduced incidence compared to a previously reported series. ${ }^{16}$ This could be due to the results of effective national prevention programs and a more precise analysis of the cases by the multidisciplinary panel.

Previously described risk factors for the perpetrators of AHT are young parental age, low educational and low socioeconomic-cultural level, family instability, ${ }^{4,7-9}$ alcoholism, and drug abuse. ${ }^{3,11}$ We were unable to verify in these series the influence of young parental age, although there were some very young parents ( $<19$ years) in the AHT group. However, unbalanced families with socioeconomic problems and low cultural level were clearly more numerous in the AHT group. This underlines the need for efficient and specific preventive measures in families identified as at risk, as highlighted by other authors. ${ }^{22-25}$ As in other reports, boys represented more than $65 \%$ of the population, and most children were aged under one year. $2,4-8,11,12,16,17$

The absence of reported trauma or an informed clinical history that does not match the severity of injuries has been cited as $92 \%$ predictive for abuse/aggression. ${ }^{4}$ Often in the cases of AHT, the perpetrator is their own witness, the victim is usually aged under one year, and the most frequent brain injury is SDH. ${ }^{12,26}$ Severe nAHT remains very unusual in children aged under 12 months and mainly results from witnessed traumas such as traffic accidents or falls from heights; isolated SDH, however, is found in these cases only exceptionally. ${ }^{27,28}$ For these reasons, all head injuries occurring in children aged under two years without a clear witnessed history of an accident must be considered as a potential victim of AHT at first glance, requiring further investigations, including an ophthalmologic exam, complete skeletal bone radiographs, and EEG. ${ }^{7,16,19,21,29}$ In some cases, nAHT occurs at home as the result of falls, but this mostly occurs in older children and is immediately described by parents and caregivers. In our nAHT group, careful further inquiries led to the identification of possible accidental mechanisms compatible with the brain injuries observed in all cases. These home accidents were frequently only witnessed by other children or underestimated by caregivers and could therefore be initially overlooked as potential severe head trauma by adult caregivers. ${ }^{12,28}$

In AHT, a scenario of aggression is described that begins with a child who "cries a lot." Typically, young and stressed parents or caregivers fail to stop a baby from crying, get angrier, lose self-control, and begin shaking the child in an aggressive way or attacking them physically in other ways. ${ }^{11,30}$ The mechanism usually underlying this type of trauma is rapid acceleration, deceleration, and rotation of the child's skull during repeated and forceful shaking by an aggressor holding and lifting the child by the chest or arms. $^{5,11}$ The high prevalence of intracranial hypertension, epilepsy, and status epilepticus, ${ }^{16,31}$ that, together, are responsible for $78 \%$ of the clinical manifestations diagnosed in hospital admissions in this study, demonstrate the severity of this trauma mechanism. Compared with a previous study, ${ }^{32}$ we observed that children aged under 1 year who experience an "accidental fall" or "home-related injury" seldom present with the symptoms described here upon hospital admission.
Although falls are extremely common in the same age group as the victims of AHT, the biomechanics of these injuries are different in terms of the acceleration, rotation, deceleration, and final impact. ${ }^{28}$

Recurrent aggression was identifiable in up to $20 \%$ of cases, frequently leading to repeated visits to the emergency department for medical assistance. ${ }^{7,11}$ Prompt recognition of the problem and adequate explorations leading to the early diagnosis of AHT could be life-saving, preventing further aggression. ${ }^{14}$ In our sample, $44 \%$ of children with suspected AHT had a history of medical care before diagnosis. Impaired or delayed neurodevelopment and other disabilities, ${ }^{15}$ low birth weight, previous hospitalization, or prematurity are commonly reported in victims of AHT. ${ }^{2,4-8,11,12,16,17}$ Comorbidities were recorded in 46\% (nAHT) and 37\% (AHT) of our population. Macrocephaly, with a previous diagnosis of external hydrocephalus, was the most common. The presence of enlarged subdural spaces, relatively tensed bridge veins, cranial disproportion, an immature brain, and open sutures and fontanels potentially put these children at increased risk of vascular and parenchymal lesions, resulting from acceleration and deceleration movements. ${ }^{33}$

External signs of violence should be systematically ruled out. $^{12,19,21}$ When no external signs of violence/impact are evident, doubt can persist regarding the trauma mechanism. ${ }^{4,7,20,21,34}$ Although more frequent in Group 2 (AHT), burns (from cigarette butts or other agents), skin abrasions, bruises, hematoma, subcutaneous cranial impact, and bite marks were noted in fewer than $50 \%$ of our cases. The presence of external signs are valuable for predicting AHT, but their absence must not eliminate the possibility of abuse. $^{4,7,20,29}$

The most common CT findings of AHT include isolated $\mathrm{SDH}$, which is present in more than $70 \%, 6,16,20,29,34,35$ commonly bilateral, and sometimes associated with interhemispheric and/or convexity hyperdensity. ${ }^{20,33,35}$ As we examined children aged under 2 years presenting with at least one traumatic intracranial injury on initial CT scan and without a clear history of trauma, excluding all traffic- and fall-related injuries, SDH was an almost constant finding in both groups. A potential mechanism of shaking with an isolated SDH was the most frequent situation (91\%), and a shaking-impact mechanism has occurred in $8 \%$ of cases. In our previously described population of children with severe nAHT, ${ }^{27,28}$ we observed that the most frequently identified injuries were brain swelling, skull fractures, and multiple brain contusions, with isolated SDH present in fewer than $2 \%$ of cases. Isolated SDH is rare in victims of home accidents aged under one year; however, skull fractures (linear or depressed) are the most frequently reported lesions. ${ }^{32,35}$

An ophthalmologic evaluation for $\mathrm{RH}$ is a prerequisite in all infants and toddlers presenting with a severe head injury. In AHT, RH is usually diffuse and bilateral, ${ }^{19,29,36-38}$ highlighting the violence of acceleration and deceleration, $11,35,39,40$ and present in over $50 \%$ of cases. $6,11,17,19-21,34$ In our sample, $79 \%$ of children in the AHT group had $\mathrm{RH}$, and of those, it was bilateral in $77 \%$. $\mathrm{RH}$ cannot be considered specific to AHT because it is rarely observed in nAHT 
involving acceleration, deceleration, and impact, such as falls from heights or traffic accidents. However, in these cases, $\mathrm{RH}$ is generally smaller and unilateral, $7,11,19,31,37$ as we verified.

Associated skeletal lesions are frequently metaphyseal in the tibia, femur, humerus, and posterior aspect of the ribs. ${ }^{4,7,19-21,39,40}$ Extracranial fractures were more frequent in children with suspected AHT (18\%) compared with those with nAHT (6\%; $\rho=0.04)$, highlighting the importance of skeletal radiography in all children with suspected AHT. However, the absence of bone fractures in skeletal radiographs cannot exclude the possibility of AHT.

AHT should be considered a severe traumatic brain injury, with a high risk of evolutive complications, long-term disabilities, and mortality, requiring early aggressive specialized management. ${ }^{39-42}$ Although isolated inaugural seizures are a common finding in infants and toddlers in both groups, AHT carries a major risk of status epilepticus development that must be taken into account as soon as possible. Uncontrolled epilepsy is present in a large proportion of survivors of AHT. ${ }^{11,16}$ A bad outcome with severe disabilities, visual deficits, and epilepsy occurs in $36 \%$ of the survivors, contrasting with a bad outcome in $10 \%$ of the children with nAHT. Monitoring these children, particularly for the identification of disabilities, should be undertaken by a multidisciplinary team comprising a pediatric neurosurgeon, neurologist, ophthalmologist, pediatricians, and specialists in developmental behavioral disorders. ${ }^{16,41,42}$ It is also worth noting that neurologic disabilities resulting from AHT or nAHT sometimes manifest after the first 6 months, the scope of this study did not include their identification after this period.

The mortality rates of AHT vary from $15-35 \% .6,7,10,11$ Therefore, our $4 \%$ mortality rate seems to be underestimated. One possible explanation could be the selection bias, because the most severely injured children who died early could not be referred to our center. Another possible explanation could be that battered infants, representing less than $10 \%$ of our population, could have been dispatched to other pediatric intensive care units, with the neurosurgical problem being considered as non-dominant in these children. However, this bias highlights the possibility of underestimating the incidence of AHT and the fact that some health providers do not consider it a primary neurosurgical emergency. ${ }^{7,10}$

\section{Conclusion}

AHT must always be considered and treated as a serious brain injury. The association of an unconvincing history of severe trauma, isolated SDH, and retinal hemorrhages (mainly bilateral and diffuse) should be systematically investigated as intentional or non-accidental trauma. The absence of external signs of abuse or bone fractures, under any circumstances, eliminates the suspicion of AHT. In some cases, careful inquiries could identify a mechanism of injury compatible with the observed lesions that, in these cases, differs significantly from those observed in documented cases of AHT. It must be emphasized that this study, which is based on our experience at a single French center for the treatment of AHT, may not reflect the reality at other centers. However, early recognition, adequate exploration, and aggressive management are warranted and are the keys to limiting the immediate complications and long-term disabilities arising from AHT.

\section{Acknowledgment}

Mireille Amona and Christelle Custos (social workers of the Necker Hospital) for their help in searches of social histories of families.

\section{References}

1 Al-Holou WN, O'Hara EA, Cohen-Gadol AA, Maher CO. Nonaccidental head injury in children. Historical vignette. J Neurosurg Pediatr 2009;3(6):474-483

2 Barlow KM, Minns RA. Annual incidence of shaken impact syndrome in young children. Lancet 2000;356(9241):1571-1572

3 Case ME. Abusive head injuries in infants and young children. Leg Med (Tokyo) 2007;9(2):83-87

4 Gerber P, Coffman K. Nonaccidental head trauma in infants. Childs Nerv Syst 2007;23(5):499-507

5 Ghahreman A, Bhasin V, Chaseling R, Andrews B, Lang EW. Nonaccidental head injuries in children: a Sydney experience. J Neurosurg 2005;103(3, Suppl)213-218

6 Scavarda D, Gabaudan C, Ughetto F, et al. Initial predictive factors of outcome in severe non-accidental head trauma in children. Childs Nerv Syst 2010;26(11):1555-1561

7 Sieswerda-Hoogendoorn T, Boos S, Spivack B, Bilo RAC, van Rijn RR. Educational paper: Abusive Head Trauma part I. Clinical aspects. Eur J Pediatr 2012;171(3):415-423

8 Sun DTF, Zhu XL, Poon WS. Non-accidental subdural haemorrhage in Hong Kong: incidence, clinical features, management and outcome. Childs Nerv Syst 2006;22(6):593-598

9 Dubowitz H, Bennett S. Physical abuse and neglect of children. Lancet 2007;369(9576):1891-1899

10 Kesler H, Dias MS, Shaffer M, Rottmund C, Cappos K, Thomas NJ. Demographics of abusive head trauma in the Commonwealth of Pennsylvania. J Neurosurg Pediatr 2008;1(5):351-356

11 Matschke J, Herrmann B, Sperhake J, Körber F, Bajanowski T, Glatzel M. Shaken baby syndrome: a common variant of nonaccidental head injury in infants. Dtsch Arztebl Int 2009;106(13): 211-217

12 Vinchon M, de Foort-Dhellemmes S, Desurmont M, Delestret I. Confessed abuse versus witnessed accidents in infants: comparison of clinical, radiological, and ophthalmological data in corroborated cases. Childs Nerv Syst 2010;26(5):637-645

13 Jacobi G, Dettmeyer R, Banaschak S, Brosig B, Herrmann B. Child abuse and neglect: diagnosis and management. Dtsch Arztebl Int 2010;107(13):231-239, quiz 240

14 Adamsbaum C, Grabar S, Mejean N, Rey-Salmon C. Abusive head trauma: judicial admissions highlight violent and repetitive shaking. Pediatrics 2010;126(3):546-555

15 Jones L, Bellis MA, Wood S, et al. Prevalence and risk of violence against children with disabilities: a systematic review and metaanalysis of observational studies. Lancet 2012;380(9845):899-907

16 Bourgeois M, Di Rocco F, Garnett M, et al. Epilepsy associated with shaken baby syndrome. Childs Nerv Syst 2008;24(2):169-172, discussion 173

17 Meyer PG, Ducrocq S, Rackelbom T, Orliaguet G, Renier D, Carli P. Surgical evacuation of acute subdural hematoma improves cerebral hemodynamics in children: a transcranial Doppler evaluation. Childs Nerv Syst 2005;21(2):133-137

18 Ewing-Cobbs L, Prasad MR, Kramer L, et al. Late intellectual and academic outcomes following traumatic brain injury sustained during early childhood. J Neurosurg 2006;105(4, Suppl)287-296 
19 Kemp AM. Abusive head trauma: recognition and the essential investigation. Arch Dis Child Educ Pract Ed 2011;96(6):202-208

20 Fanconi M, Lips U. Shaken baby syndrome in Switzerland: results of a prospective follow-up study, 2002-2007. Eur J Pediatr 2010; 169(8):1023-1028

21 Feldman KW, Bethel R, Shugerman RP, Grossman DC, Grady MS, Ellenbogen RG. The cause of infant and toddler subdural hemorrhage: a prospective study. Pediatrics 2001;108(3):636-646

22 Barr RG, Barr M, Fujiwara T, Conway J, Catherine N, Brant R. Do educational materials change knowledge and behaviour about crying and shaken baby syndrome? A randomized controlled trial. CMAJ 2009;180(7):727-733

23 Barr RG. Preventing abusive head trauma resulting from a failure of normal interaction between infants and their caregivers. Proc Natl Acad Sci U S A 2012;109(Suppl 2):17294-17301

24 Macmillan HL, Wathen CN, Barlow J, Fergusson DM, Leventhal JM, Taussig HN. Interventions to prevent child maltreatment and associated impairment. Lancet 2009;373(9659):250-266

25 Ward MGK, Bennett S, King WJ. Prevention of shaken baby syndrome: Never shake a baby. Paediatr Child Health (Oxford) 2004;9(5):319-321

26 Vinchon M, Desurmont M, Soto-Ares G, De Foort-Dhellemmes S. Natural history of traumatic meningeal bleeding in infants: semiquantitative analysis of serial CT scans in corroborated cases. Childs Nerv Syst 2010;26(6):755-762

27 Tude Melo JR, Di Rocco F, Blanot S, et al. Mortality in children with severe head trauma: predictive factors and proposal for a new predictive scale. Neurosurgery 2010;67(6):1542-1547

28 Melo JRT, Di Rocco F, Lemos-Júnior LP, et al. Defenestration in children younger than 6 years old: mortality predictors in severe head trauma. Childs Nerv Syst 2009;25(9):1077-1083

29 Piteau SJ, Ward MGK, Barrowman NJ, Plint AC. Clinical and radiographic characteristics associated with abusive and nonabusive head trauma: a systematic review. Pediatrics 2012; 130(2):315-323

30 Reijneveld SA, van der Wal MF, Brugman E, Sing RAH, VerlooveVanhorick SP. Infant crying and abuse. Lancet 2004;364(9442): $1340-1342$
31 Trenchs V, Curcoy AI, Morales M, Serra A, Navarro R, Pou J. Retinal haemorrhages in- head trauma resulting from falls: differential diagnosis with non-accidental trauma in patients younger than 2 years of age. Childs Nerv Syst 2008;24(7):815-820

32 Galarza M, Gazzeri R, Barceló C, et al. Accidental head trauma during care activities in the first year of life: a neurosurgical comparative study. Childs Nerv Syst 2013;29(6):973-978

33 Ewing-Cobbs L, Prasad M, Kramer L, et al. Acute neuroradiologic findings in young children with inflicted or noninflicted traumatic brain injury. Childs Nerv Syst 2000;16(1):25-33, discussion 34

34 Graupman P, Winston KR. Nonaccidental head trauma as a cause of childhood death. J Neurosurg 2006;104(4, Suppl) 245-250

35 Case ME, Graham MA, Handy TC, Jentzen JM, Monteleone JA; National Association of Medical Examiners Ad Hoc Committee on Shaken Baby Syndrome. Position paper on fatal abusive head injuries in infants and young children. Am J Forensic Med Pathol 2001;22(2):112-122

36 Binenbaum G, Rogers DL, Forbes BJ, et al. Patterns of retinal hemorrhage associated with increased intracranial pressure in children. Pediatrics 2013;132(2):e430-e434

37 Gabaeff SC. Challenging the Pathophysiologic Connection between Subdural Hematoma, Retinal Hemorrhage and Shaken Baby Syndrome. West J Emerg Med 2011;12(2):144-158

38 Hylton C, Goldberg MF. Images in clinical medicine. Circumpapillary retinal ridge in the shaken-baby syndrome. $\mathrm{N}$ Engl J Med 2004;351(2):170

39 Duhaime AC, Christian CW, Rorke LB, Zimmerman RA. Nonaccidental head injury in infants-the "shaken-baby syndrome". N Engl J Med 1998;338(25):1822-1829

40 Wissow LS. Child abuse and neglect. N Engl J Med 1995;332(21): 1425-1431

41 Glick JC, Staley K. Inflicted traumatic brain injury: advances in evaluation and collaborative diagnosis. Pediatr Neurosurg 2007; 43(5):436-441

42 Trenchs V, Curcoy AI, Navarro R, Pou J. Subdural haematomas and physical abuse in the first two years of life. Pediatr Neurosurg 2007;43(5):352-357 